\section{A "reforma agrária assistida pelo mercado" do Banco Mundial no Brasil: dimensões políticas, implantação e resultados}

João Márcio Mendes Pereira ${ }^{1}$ e Sérgio Sauer ${ }^{2}$

Resumo: O artigo analisa a implementação e os resultados do projeto piloto Cédula da Terra (1997-2002) e a sua continuidade, a partir de 2003, por meio do Programa Nacional de Crédito Fundiário. Tais iniciativas foram inspiradas na proposta de "reforma agrária assistida pelo mercado", impulsionada pelo Banco Mundial em diversos países, em particular na América Latina, a partir de 1994, como alternativa à reforma agrária, a qual está em curso, nos dias atuais, apenas no Brasil. Com base em pesquisas empíricas, argumenta-se que o Cédula da Terra, ao contrário do que afirma o Banco Mundial, não foi bem sucedido em prover um modelo de acesso à terra a ser reproduzido em maior escala. Este artigo faz ainda um balanço dos desdobramentos desse modelo na política fundiária do governo Luis Inácio Lula da Silva (2003-2010).

Palavras-chave: Banco Mundial, Cédula da Terra, Crédito Fundiário, Pobreza Rural, Reforma Agrária
Recebido:

28/07/10

Aprovado

01/11/11

1. Professor adjunto do Departamento de História e do Programa de Pós-Graduação em História da Universidade Federal Rural do Rio de Janeiro (UFRRJ).

2. Professor da Faculdade da UnB de Planaltina (FUP/ UnB) e dos Programas de Pós Graduação em Meio Ambiente e Desenvolvimento Rural (PPG-MADER) e em Agronegócios (Propaga - FAV/UnB).

O êxito da nova geração de projetos de reforma agrária na África do Sul, no Brasil e na Colômbia estabelece um modelo alternativo (...) às reformas agrárias administrativas que pode servir de base para a experimentação em outros países.

Banco Mundial (1998, p. 4)

O modelo de reforma agrária através da distribuição de terras pelo governo é um círculo vicioso: a terra é redistribuída onde há conflitos sociais e os conflitos sociais pressionam o programa de redistribuição de terras do governo (...). À medida que novas alternativas começam a fazer efeito, o governo poderá reduzir a ênfase nas desapropriações e, conseqüentemente, quebrar a ligação entre sua política de reforma agrária e os conflitos rurais.

Banco Mundial (2003, p. 127) 
A assim denominada "reforma agrária assistida pelo mercado" (marketassisted land reform ou RAAM), concebida e impulsionada pelo Banco Mundial (BIRD), teve início com a execução de dois empréstimos no Brasil, sendo um restrito ao estado do Ceará (1997) e outro implantado em cinco estados do Nordeste (incluindo o próprio Ceará), por meio do "Projeto-Piloto de Reforma Agrária e Alívio da Pobreza", mais conhecido como Cédula da Terra. A partir de 2003, já no Governo Lula (2003-2010), esse modelo teve sua continuidade por meio da criação e execução do Programa Nacional de Crédito Fundiário.

O Cédula da Terra foi executado entre 1997 e 2002 e recebeu fortes críticas de todos os movimentos sociais agrários e entidades sindicais de representação de trabalhadores rurais. Apesar disso, o BIRD alega que o Cédula representou uma experiência exemplar, por isso mesmo replicável em maior escala como modelo preferencial de acesso à terra por trabalhadores rurais sem terra ou com terra insuficiente para a sua reprodução social. No entanto, várias pesquisas - inclusive as financiadas pelo próprio BIRD - contestaram o diagnóstico oficial. Este artigo segue nessa direção, argumentando que o desempenho e os resultados do Cédula não corroboram o discurso do Banco Mundial.

Além de expressão clara de uma política governamental baseada na lógica de mercado (lei da oferta e da procura por terras), tais programas explicitam embates de longa data entre o poder político central (Executivo Federal) e setores organizados da sociedade brasileira. Malgrado o discurso do Banco Mundial em prol da promoção do "protagonismo social" e do "empoderamento dos pobres", os enfrentamentos em torno desses programas expressam um descompasso entre as reivindicações históricas pelo acesso à terra e a natureza da política social para o campo, posta em prática pelos governos federais nas últimas décadas, centrada no "aliviamento da pobreza".

Inicialmente, aborda o contexto político que deu sustentação à implantação da RAAM no Brasil, a partir do Governo FHC (1995-2002). Depois, analisa o desempenho e os problemas na implantação do Cédula. Por fim, traça um breve balanço das mudanças no modelo patrocinado pelo BIRD no Brasil e dos seus desdobramentos na política fundiária do governo Lula.

É importante salientar que, no debate internacional sobre a RAAM, acabaram se desenhando três posições principais (PEREIRA, 2010). Uma primeira exaltou as potencialidades do modelo, atribuindo as causas dos problemas observados nos programas a falhas de ordem técnica e operacional. Nessa vertente, entrincheiraram-se os setores do Banco Mundial, responsáveis pela criação dessa proposta e intelectuais e apoiadores locais desse modelo (VAN ZYL, KIRSTEN \& BINSWANGER, 1996; DEININGER \& BINSWANGER, 1999; 
BANCO MUNDIAL, 2003b; BUAINAIN, SILVEIRA \& TEÓFILO, 2000; TEÓFILO, 2003).

Uma segunda posição defendeu a experimentação da RAAM, porém com críticas pontuais a limitações e problemas considerados inerentes ao modelo. Aqui se alinharam especialistas em desenvolvimento rural ligados diretamente a (ou com trânsito em) organismos internacionais. Favoráveis a políticas fundiárias centradas na dinamização e liberalização dos mercados de terra, chamavam atenção para dois limites básicos do modelo: o seu custo elevado e a sua incapacidade de alcançar escala social, em decorrência do pagamento à vista e a preço de mercado aos proprietários de terra (DE JANVRY \& SADOULET, 2001; GORDILLO, 2002; BANERJEE, 1999; JARAMILLO, 1998; BURKI \& PERRY, 1997).

Uma terceira posição - com a qual este trabalho se identifica - salientou a natureza socialmente regressiva da RAAM, à luz dos resultados empiricamente constatados em diversos países (como Brasil, Guatemala, Colômbia e África do Sul). Ademais, essa vertente se preocupou em evidenciar a relação intrínseca entre a RAAM e a sua matriz política - a reestruturação capitalista neoliberal - dimensão tomada simplesmente como algo dado e, portanto, não questionável, pelas vertentes anteriores (EL-GHONEMY, 2001; BARROS, SCHWARTZMAN \& SAUER, 2003; BORRAS JR., 2006, 2003 e 2003a; GAROZ et al., 2005; SAUER \& PEREIRA, 2006; PEREIRA, 2005, 2006 e 2010; SAUER, 2010; LAHIFF, BORRAS JR. \& KAY, 2007).

Disputas políticas em torno do acesso à terra no Brasil em meados dos anos 1990

Para a coalizão de poder que levou Fernando Henrique Cardoso (1995-2002) à Presidência da República, "reforma agrária" era algo anacrônico. Segundo a leitura então dominante, às portas do século XXI, o tema significava, no máximo, a realização de ações focalizadas de aliviamento da pobreza rural, sem qualquer pretensão redistributiva. Não por acaso, no início do governo FHC, a "reforma agrária" era vinculada ao programa Comunidade Solidária, de caráter notoriamente assistencialista (CARVALHO Fo, 2001).

Entretanto, o aumento das ocupações de terra, conjugado à forte repercussão nacional e internacional dos massacres de Corumbiara (Rondônia, 1996) e, sobretudo, Eldorado dos Carajás (Pará, 1997), impuseram ao governo federal o reconhecimento da existência de um "problema agrário" no país. A necessidade de dar resposta à opinião pública forçou o governo a criar, em 1996, o Ministério Extraordinário de Política Fundiária (MEPF). Um ano depois, o MST promoveu a Marcha Nacional por Reforma Agrária, Emprego e Justiça, catalisando a insatisfação popular contra a política econômica e as reformas neoliberais. 
Naquele momento, ficou claro que o governo federal não tinha condições de neutralizar a pressão social pelo acesso à terra e por reforma agrária utilizando apenas os instrumentos então disponíveis.

Para reverter a posição desfavorável na qual havia sido colocado, o governo adotou o discurso de que era preciso "reformar a reforma agrária" (CARDOSO, 1997, p. 25). O MEPF, assim, iniciou um conjunto relativamente articulado de ações em cinco direções. Em primeiro lugar, editou um pacote de medidas com o objetivo de reduzir o preço final pago pelo Estado às desapropriações, acelerar o tempo de imissão na posse da terra desapropriada pelo INCRA e dificultar a evasão do ato desapropriatório pelos proprietários de terra (MEDEIROS, 2002).

Em segundo lugar, aumentou a criminalização das ocupações de terra, proibindo a realização de vistorias do INCRA em áreas ocupadas (o que inviabilizava a sua desapropriação), suspendendo negociações em casos de ocupação de órgão público, penalizando funcionários do INCRA que negociassem com os ocupantes e vetando o acesso a recursos públicos por entidades que fossem consideradas suspeitas de envolvimento direto ou indireto com ocupações de terra (MEDEIROS, 2002). Ao mesmo tempo, acionou a Polícia Federal para monitorar a ação dos movimentos sociais.

Em terceiro lugar, por meio dos grandes meios de comunicação, promoveu uma campanha de convencimento para construir uma imagem positiva do governo em relação à reforma agrária e uma imagem negativa das ocupações de terra, num período em que crescia o apoio social ao MST (CARVALHO Fo., 2001). Em quarto lugar, contra a posição de todas as entidades reunidas no Fórum Nacional pela Reforma Agrária e Justiça no Campo (FNRA, que reúne as principais entidades e movimentos sociais agrários), tomou iniciativas no sentido de desfederalizar a política de reforma agrária, transferindo para a esfera estadual a competência para a condução do processo de obtenção de terras e assentamento, convertendo-a em um caso-a-caso negociado localmente. Em quinto lugar, o governo federal deu início a uma política agrária "baseada no mercado", por meio da implantação do Cédula da Terra, a partir de empréstimos do BIRD.

Já em 1995, no rastro da implantação da RAAM, na Colômbia e na África do Sul, o BIRD preconizava ao governo brasileiro o financiamento de transações mercantis entre agricultores e proprietários como o mecanismo mais eficiente para distribuir terra, aliviar a pobreza rural e dinamizar os mercados fundiários (BANCO MUNDIAL, 1995). Segundo os técnicos da instituição, o governo deveria criar imediatamente uma "rede de proteção" focalizada nos segmentos mais pobres que aliviasse o impacto do Plano Real e das políticas de ajustamento estrutural no campo (VAN ZYL et al., 1995). O acesso à terra seria um dos componentes dessas políticas compensatórias, sendo que a novidade era que 
tal acesso deveria se dar pela via da negociação mercantil entre agentes privados financiada pelo Estado.

Na leitura dos técnicos do BIRD, o Brasil oferecia, então, condições ideais como campo de teste em larga escala da RAAM: enorme demanda por terra, tendência de queda relativa do preço dos imóveis rurais em algumas regiões e, sobretudo, um governo politicamente alinhado ao programa neoliberal. Por sua vez, pelo lado do governo, era preciso não apenas dar respostas imediatas ao aumento da pressão social por terra, mas também pautar a maneira pela qual a problemática agrária devia ser tratada institucionalmente. Foi essa convergência de interesses que possibilitou a introdução de projetos e programas orientados pelo modelo de RAAM no Brasil.

Repetindo as mesmas justificativas do Banco Mundial (1997b), o governo brasileiro sustentou três argumentos em favor da RAAM. Em primeiro lugar, afirmou que a desapropriação para fins de reforma agrária havia se tornado um instrumento anacrônico e inadequado, posto que intrinsecamente vinculado a um modelo de ação fundiária centralizador, arbitrário, propenso à corrupção e lento. Nessa lógica, seria preciso substituir esse instrumento por mecanismos mais eficientes, baseados na livre transação mercantil entre agentes privados (TEÓFILO, 2003).

Em segundo lugar, o governo federal argumentou que o orçamento da União não tinha condições de financiar um programa efetivo de reforma agrária, dadas as indenizações elevadas arbitradas pelo Judiciário (TEÓFILO, 2003). Além de ineficaz e anacrônico, o modelo desapropriacionista seria caro demais. Era fundamental criar outras fontes de recursos para os programas agrários, sendo que o BIRD estava oferecendo tais recursos.

Em terceiro lugar, o discurso oficial era de que as ações do governo estavam a reboque dos movimentos sociais - especialmente do MST - uma vez que os assentamentos resultavam, predominantemente, de ocupações e acampamentos. Era preciso, então, diminuir o número de ocupações de terra e esvaziar a ascensão das lutas sociais no campo, introduzindo um mecanismo capaz de disputar a adesão de trabalhadores rurais (CARVALHO Fo, 2001).

O primeiro projeto desse tipo, criado em agosto de 1996, chamou-se "Reforma Agrária Solidária", uma experiência pequena restrita ao estado do Ceará ${ }^{\text {. Foi }}$ dessa experiência que nasceu, poucos meses depois, o projeto piloto Cédula da Terra, a partir da proposta do BIRD ao governo brasileiro (MEPF, 1999). Assim, essa experiência foi estendida também para Pernambuco, Bahia, Maranhão e norte de Minas Gerais, por meio de novo acordo de empréstimo aprovado pelo BIRD, em abril de 1997.
3. O governo do Ceará criou, em 1996, um fundo estadual e aportou pouco mais de $\mathrm{R} \$ 4 \mathrm{mi}-$ Ihões, complementados por um empréstimo do BIRD de $\mathrm{R} \$$ milhões. $\mathrm{O}$ objetivo era financiar a compra de 40 mil hectares por 800 famílias durante um ano. Na práti$\mathrm{ca}$, financiou a compra de 44 imóveis por 694 famílias, totalizando 23.622 hectares, sendo que o projeto estimulou a elevação do preço da terra onde foi implantado (PEREIRA, 2010) 
Repetindo o mesmo procedimento usado em outros países, o BIRD propôs a implantação de um projeto piloto com metas relativamente modestas - financiar a compra de terras por quinze mil famílias em quatro anos - para criar as condições políticas para a extensão do modelo de RAAM a todo país (PEREIRA, 2010). Como revela um documento do BIRD: "Se o projeto-piloto demonstrar a viabilidade da reforma agrária assistida pelo mercado e as estimativas de custos para este piloto forem representativas do país (...), tal programa poderia atender um milhão de famílias em menos de seis anos" (BANCO MUNDIAL, 1997b, p. 7).

A região escolhida para iniciar o novo modelo foi o meio rural nordestino, onde se concentra o maior contingente de população em condições de pobreza do país e onde o BIRD opera desde os anos 1970. Desse modo, contando com uma logística já existente, e frente a uma elevada "demanda" por terra, estimava-se que a implantação do projeto piloto ocorreria de maneira acelerada e daria rápidos resultados (BANCO MUNDIAL, 1997a).

Enquanto o projeto piloto era implantado, tramitava no Senado o Projeto de Lei no 25 , que previa a criação de um fundo público para o financiamento de compra e venda de terras para pequenos agricultores e trabalhadores rurais (MEPF, 1999). Sem qualquer tipo de avaliação sobre as experiências em curso e contra a posição do FNRA, a base parlamentar do governo conseguiu aprovar a criação do chamado Fundo de Terras/Banco da Terra, em fevereiro de 1998. Segundo o MEPF: "o Banco da Terra é a expansão, para todo o país, dessa experiência pioneira e bem-sucedida de reforma agrária, desenvolvida pelo governo brasileiro em parceria com o Banco Mundial. Tudo começou em 1997 no Ceará, com o nome de 'Projeto São José'” (MEPF, 1999, p. 14).

Uma das linhas de argumentação usadas pelos parlamentares do bloco governista, durante a única sessão na Câmara dos Deputados de discussão sobre o Banco da Terra, foi o sinal de que o BIRD aportaria mais recursos (PEREIRA, 2010). O próprio BIRD, inicialmente, assumiu a paternidade do Banco da Terra, afirmando que o Cédula havia sido um sucesso e demonstrado "como o Banco pode facilitar inovações de política social" (BANCO MUNDIAL, 2000, § 122, item d), explicitando a intenção de aportar mais recursos para financiar a continuidade do mesmo (SAUER, 2010).

Todavia, diante da oposição das entidades do FNRA e, na sequência, da crise do Real no final de 1998, a diretoria do BIRD acabou levando mais de dois anos para aprovar e liberar o empréstimo prometido (PEREIRA, 2010 e 2007). Quando isso aconteceu, no final de 2000, os recursos não foram direcionados ao Banco da Terra, mas a um quarto programa de financiamento à compra de terras, denominado Crédito Fundiário de Combate à Pobreza Rural, a partir de uma demanda da Confederação Nacional de Trabalhadores na Agricultura (CONTAG). 
Malgrado pequenas diferenças, foram essas quatro iniciativas (Reforma Agrária Solidária, Cédula da Terra, Banco da Terra e Crédito Fundiário) que materializaram a RAAM no Brasil, implantada durante o governo FHC (PEREIRA, 2010 e 2007).

\section{Gênese: o projeto piloto Cédula da Terra}

O Cédula teve início em julho de 1997 e foi encerrado em 31 de dezembro de 2002, um ano e meio depois do prazo originalmente previsto. Os objetivos oficiais eram: a) reduzir a pobreza rural, por meio do aumento da renda familiar; b) elevar o rendimento agrícola; c) testar o modelo de mercado como alternativa ao modelo tradicional de reforma agrária (BUAINAIN et al., 1999). Na base de todo construto estava a busca por um modelo de política fundiária mais barato, a fim de reduzir o gasto público para a área social exigido pelo ajuste fiscal. O público alvo eram trabalhadores sem terra (assalariados, parceiros, arrendatários) e agricultores com terra insuficiente para a subsistência. O acesso ao projeto só podia ser feito através de associações comunitárias legalmente constituídas, preexistentes ou criadas para esse fim.

Com implementação esperada para quatro anos, o financiamento do Cédula teve quatro fontes, sendo que o BIRD (U\$ 90 milhões) e o governo federal (U\$ 45 milhões) foram as principais. Os recursos para a compra de terras viriam do governo federal e os do BIRD deveriam ser utilizados apenas para investimentos complementares. O programa contou também com aportes dos governos estaduais (U\$ 6,6 milhões) e das associações (U\$ 8,4 miIhões) (BANCO MUNDIAL, 1997b). Ao final, foram aportados U\$ 68,5 milhões pelo BIRD e apenas U\$ 1,9 milhões pelos governos estaduais, totalizando um investimento de U\$ 121,3 milhões até 2002 (BANCO MUNDIAL, 2003a).

O projeto foi parcialmente paralisado no final de 1999 e parte de 2000, devido à falta de aporte de recursos pelo governo federal durante a crise financeira do Real (BANCO MUNDIAL, 2003a) e às duas solicitações de investigação do FNRA ao Painel de Inspeção, órgão interno responsável pela fiscalização das ações do BIRD. Com a desvalorização do Real pós-1999, houve uma redução do custo final do Cédula em moeda estrangeira, diminuindo o aporte final do projeto piloto.

\begin{tabular}{|c|c|c|}
\hline Itens financiados & Gasto previsto & Gasto efetivo \\
\hline Compra de terras & 45 & 45 \\
\hline Investimentos complementares & 84,3 & 66.4 \\
\hline Assistência técnica e capacitação & 3,9 & 2,6 \\
\hline $\begin{array}{l}\text { Monitoramento, supervisão e } \\
\text { administração }\end{array}$ & 10,1 & 2,1 \\
\hline Avaliação e propaganda & 6,7 & 5,2 \\
\hline Total & 150 & 121,3 \\
\hline
\end{tabular}


4. O SAT financiava a aquisição de imóveis com prazo de amortização de dez anos, sendo três anos de carência e correção monetária pela TJLP. Em 1999, o governo modificou as condições de financiamento, ajustando-as às condições então oferecidas pelo Banco da Terra (MEPF, 1999), com prazo de amortização de vinte anos e juros de $4 \%$ ao ano mais correção monetária pelo Índice Geral de Preços da Fundação Getúlio Vargas. Em fevereiro de 2002, a taxa de juros foi elevada para $6 \%$ ao ano.

5. O SIC provia recursos a fundo perdido para investimentos comunitários em infraestrutura (eletrificação, melhoramento de estradas, fornecimento de água, etc.), social (melhoria de escola ou posto de saúde, centro comunitário, etc.) e produtivos (irrigação, agroprocessamento em pequena escala, tratores, etc.).

6. Além disso, os gastos incluíam ainda registro, medição, impostos, sendo que havia um limite máximo de subsídio de US\$ 6.900 por família (investimentos), e cada uma podia receber US\$ 1.300 a fundo perdido como ajuda para instalação.
Seguindo a mesma lógica do projeto Reforma Agrária Solidária, o Cédula foi dividido em dois subcomponentes, um voltado para a aquisição de terra (SAT) $)^{4}$ outro para investimentos complementares $(\mathrm{SIC})^{5}$, sendo que o limite de crédito para cada família era de US\$11.200, incluídos os gastos com a compra da terra ${ }^{6}$. A lógica de financiamento era de que quanto menor fosse o gasto com a compra da terra (considerada empréstimo), maior seria o volume de recursos a fundo perdido para investimentos complementares. O financiamento era tomado em caráter solidário, de modo que as associações eram as responsáveis legais pelo pagamento das prestações. Amortizado o empréstimo, cada família receberia o título de propriedade correspondente.

A compra de imóveis rurais deveria seguir alguns critérios, como: a) priorizar propriedades com potencial produtivo e baixo nível de investimento adicional; b) seguir os preços de mercado, levando em conta a localização, a fertilidade natural e o potencial econômico da terra; c) seguir todos os requisitos legais que regem o registro e a transferência de imóveis rurais; d) adquirir terras com boas condições de acesso, fornecimento de água e razoável infraestrutura, numa área suficiente, igual ou superior ao módulo mínimo de parcelamento da região.

Oficialmente, as associações comunitárias selecionariam o imóvel e negociariam o preço diretamente com o proprietário. Depois, apresentariam a proposta de aquisição do imóvel e a lista de subprojetos comunitários ao órgão responsável pela gestão do Cédula. Esse órgão analisaria a proposta quanto à elegibilidade dos beneficiários e do imóvel (i.e., sua situação legal, as condições de transação e a adequação do preço negociado aos parâmetros de mercado), elaborando laudo técnico de avaliação do imóvel. Aprovada a proposta, o órgão orientaria a elaboração de projeto detalhado para aquisição de terras, emitindo parecer técnico. Os projetos para investimentos complementares (SIC) seriam elaborados por terceiros ou instituições governamentais que participassem do Cédula.

Aprovada a proposta, o Banco do Nordeste (BNB) estava autorizado a contratar o financiamento com a associação e efetuar o pagamento ao proprietário e aos prestadores dos serviços de transferência de titularidade, bem como cobrar e receber os pagamentos do financiamento de cada associação. O Banco do Nordeste também deveria repassar diretamente às associações os recursos para investimentos comunitários.

O grau de cobertura espacial do Cédula foi amplo, exceto em Minas Gerais, onde se restringiu ao norte do estado, abrangendo cinquenta municípios. A seleção dos municípios seguiu critérios como a existência de conflitos agrários latentes ou explícitos, situação de pobreza mais acentuada, existência de sindicatos de trabalhadores rurais favoráveis ao projeto, capacidade operacional da unidade técnica e apoio de prefeituras e políticos locais (BUAINAIN et al., 1999). 
O Cédula foi implementado para atingir o maior número possível de municípios, sem qualquer ligação prévia com a política oficial de reforma agrária, tampouco com uma estratégia mais ampla de desenvolvimento rural. Nos cinco estados onde foi executado, houve desaceleração do número de desapropriações para fins de reforma agrária (VICTOR \& SAUER, 2002). Aliás, nesse período inicial, podiam ser adquiridas pelo projeto áreas passíveis de desapropriação ${ }^{7}$.

Foi implantado, mas ficou longe do encontro racional e voluntário no mercado entre compradores e vendedores, como propunham os economistas do BIRD. Na verdade, como mostrou a própria avaliação preliminar do projeto ${ }^{8}$, a "demanda" pelo Cédula esteve diretamente ligada a uma situação de extrema pobreza, inexistência de oportunidades de trabalho, ação de políticos locais e repressão às ocupações de terra (PEREIRA, 2010).

O Cédula foi implantado em um período de seca e em um ano agrícola péssimo, em uma região sem perspectivas de trabalho e com uma população rural imensa e empobrecida. Num contexto com tais características, a possibilidade de acesso imediato à terra foi encarada como um meio emergencial de sobrevivência, o que conferiu ao projeto um caráter assistencial e imediatista (BUAINAIN et al., 1999, p. 30). Ademais, houve intensa propaganda exaltando a possibilidade de acesso "rápido" à terra e "sem conflitos", dirigida a uma população que, tradicionalmente, alimenta expectativas de posse da terra. Ainda, mais da metade dos projetos contabilizados em janeiro de 1999 foram implementados no segundo semestre de 1998, período eleitoral (ibidem, p. 15). A própria avaliação preliminar, financiada pelo BIRD, diagnosticou que:

Essa concepção de acesso à terra, fruto de uma "negociação entre as partes, solidária e sem conflitos" parece ser eficaz em atrair uma camada do público potencial da reforma agrária (...). Na atual conjuntura de mobilização, ao colocar nova opção de acesso à terra, o Cédula da Terra introduz uma disputa política e ideológica com outros movimentos sociais e seus mediadores (...), os quais detém, hoje, a iniciativa política neste campo e defendem o acesso à terra via instituto da desapropriação. (BUAINAIN et al., 1999, p. 280-81)

O mesmo aconteceu na sequência, pois novamente mais da metade dos projetos foi criada a partir de janeiro de 2002 (BUAINAIN et al., 2003, p. 13), outro ano eleitoral, indicando uma nova aceleração na implantação do Cédula semeIhante àquela observada no segundo semestre de $1998^{9}$. Nessa segunda fase de maior aceleração, já estava em curso a expansão dos projetos para áreas novas, iniciada a partir de 1999, de tal maneira que se tornou "muito pequena a proporção de microrregiões em cada estado que não tem assentamentos do Cédula" (ibidem, 2002, p. 87).
7. Até 2000 , os recursos para a compra de terras por meio do Cédula vieram do orçamento do INCRA, constituindo uma evidente concorrência com a reforma agrária. A partir de 2000, tais recursos passaram a ter como fonte específica o Orçamento Geral da União, sob a rubrica orçamentária do Fundo de Terras/Banco da Terra.

8. Em junho de 1999 foi concluída a avaliação preliminar (BUAINAIN et al., 1999), prevista no acordo de empréstimo como "avaliação de meio termo". o trabalho de campo foi realizado em fevereiro de 1999, com a aplicação de extenso questionário a 232 famílias, abrangendo 116 projetos, em um total de 223 projetos existentes à época.

9. Além da avaliação preliminar (Buainain et al., 1999), o BIRD financiou mais dois relatórios de avaliação do Cédula, com o objetivo de traçar o perfil socioeconômico dos beneficiários (Buainain et al., 2002) e avaliar o impacto socioeconômico do projeto (Buainain et al., 2003). 
A velocidade singular da implantação do Cédula em relação a outros projetos de "alívio da pobreza" em curso no meio rural podia ser explicada pela convergência de interesses entre os seus promotores. De um lado, os governos estaduais almejavam capitalizar eleitoralmente a sua participação no projeto nas eleições de 1998 e 2002. De outro lado, o governo federal travava uma disputa política com os movimentos sociais agrários, numa conjuntura eleitoral em que era obrigado a dar resposta ao aumento das ocupações de terra e à eclosão de saques no Nordeste por alimento (BUAINAIN et al., 1999, p. 272).

10. Em março de 2000, foi concluída a avaliação de Steil (2000), consultoria contratada pelo BIRD para avaliar o desempenho de fundos sociais e ambientais financiados no Brasil. Esse trabaIho foi feito através da análise documental e entrevistas com técnicos do BIRD, equipes estaduais responsáveis pelo Cédula, representantes da CONTAG e do governo brasileiro.

11. Em outubro de 2002, foi concluída a pesquisa sobre o desempenho do Cédula (VICTOR \& SAUER, 2002) que, entre setembro e novembro de 2001, visitou 16 projetos (total de 384 projetos à época) e entrevistou 80 famílias nos cinco estados.

\section{A situação das famílias e os resultados do projeto piloto}

Outra pesquisa financiada pelo $\mathrm{BIRD}^{10}$ mostrou que a execução do Cédula não foi objeto de controle social (STEIL, 2000). Como regra geral, as propostas de compra das áreas e os subprojetos de investimentos comunitários foram apresentados diretamente aos órgãos gestores e às unidades técnicas estaduais, esvaziando o papel dos conselhos municipais, único espaço institucional previsto para algum tipo de participação social na gestão do Cédula (STEIL, 2000).

Os imóveis rurais adquiridos estavam, na maioria dos casos, subutilizados ou abandonados, em razão da seca e da crise da pecuária e das culturas tradicionais (algodão, cacau e cana de açúcar) (BUAINAIN et al., 1999, p. 31), com índices de abandono maiores que $75 \%$ nos cinco estados (ibidem, 2003, p. 105). Em relação ao tamanho, a área média dos imóveis adquiridos foi de 815,3 hectares, em 1999, sendo que existiam apenas vinte projetos com área acima de mil e duzentos hectares (ibidem, 1999, p. 131). No entanto, Victor e Sauer (2002) detectaram a ocorrência de compra de áreas passíveis de desapropriação pelo Cédula nos cinco estados ${ }^{11}$.

A situação de pobreza e a falta de alternativas pressionaram para a entrada no Cédula, fazendo com que, de modo geral, os "beneficiários" aceitassem pagar preços mais elevados pela terra, tensionando toda a racionalidade do projeto (BUAINAIN et al., 1999, p. 120). A demanda pelo Cédula, portanto, passou longe da transação voluntária entre "compradores e vendedores", idealizada pelos economistas do Banco Mundial.

A elaboração dos projetos produtivos não se deu antes da compra dos imóveis rurais, como prevê o modelo de RAAM. Contribuiu, para o atraso dos projetos produtivos, a dificuldade das associações em obterem uma assistência técnica regular - cuja remuneração, inicialmente, não havida sido prevista pelo Cédula - que permitisse formular propostas adequadas (BUAINAIN et al., 1999, p. 195). Portanto, a aquisição dos imóveis acabou não sendo antecedida por qualquer avaliação técnica significativa a respeito das potencialidades do 
empreendimento a ser desenvolvido ${ }^{12}$.

Um dado relevante diz respeito à maneira como foram usados os recursos do SIC, em tese destinados a investimentos comunitários em infraestrutura produtiva necessários à geração de renda. Metade desses recursos foi gasta com custeio diário das famílias (BUAINAIN et al., 1999, p. 196-68 e 290), evidenciando a extrema pobreza dos demandantes e ressalta o caráter emergencial e assistencialista que o Cédula assumiu ${ }^{13}$.

A metade das aquisições de terra teve valores abaixo de $75 \%$ do valor médio do total dos contratos, o que permitiria que sobrasse, para a maioria das famílias, um montante em torno de cinco mil reais para investimentos comunitários (BUAINAIN et al., 1999, p. 138). Na prática, porém, esses recursos foram gastos de modo pulverizado em custeio e construção de infraestrutura básica (como estradas, água, luz e moradia). Disso resultou que os recursos não foram "suficientes para complementar/adaptar as benfeitorias existentes às novas condições de utilização da propriedade nem para estabelecer uma base produtiva sólida a partir da qual os beneficiários poderão gerar renda suficiente para melhorar de vida e pagar a dívida contraída" (ibidem, p. 290).

Em 2002, constatou-se novamente que os recursos do SIC haviam sido aplicados em infraestrutura (construção de casas, rede elétrica e abastecimento de água), esgotando a quantia a fundo perdido sem que fosse coberto o pacote mínimo de investimentos produtivos (ibidem, 2003, p. 100-101 e 150). Além de insuficientes, esses recursos foram também mal aplicados, em grande medida devido à "falta de controle social existente nas associações sobre a atuação de sua diretoria e o descompromisso das unidades gestoras (...). Nos assentamentos que estão em situação mais grave (alguns não têm nem casas construídas), esse fator está sempre presente e chega a inviabilizar o desenvolvimento do assentamento" (ibidem, p. 174).

Outro problema identificado foi a precariedade dos serviços de assistência técnica oferecidos (BUAINAIN et al., 1999). Além de desinformados sobre as condições gerais e o modo de funcionamento do Cédula, os técnicos atuaram de forma pontual, sem a necessária continuidade exigida a um trabalho dessa natureza. Como assinalou a avaliação preliminar:

Face a algum impasse, os técnicos têm dificuldade para decidir qual o melhor encaminhamento. Normalmente o conhecimento mais aprofundado fica sob a responsabilidade de uma só pessoa. O restante apenas "cumpre as tarefas". Além do mais, são poucos os que conseguem perceber quem são os associados e qual o perfil das associações. 0 contato entre técnicos e associados é restrito ao presidente e quando
12. No caso de Minas Gerais, não só os projetos produtivos, mas também os laudos técnicos que atestavam qualidade do solo, capacidade de suporte da área (número de famílias em relação ao tamanho da área), viabilidade econômica do empreendimento, entre outras, haviam sido elaborados após as transações de compra (Fórum, 1999).

13. Os órgãos responsáveis pela implantação do Cédula fizeram um ajuste no programa após 1999, reduzindo de trinta para vinte $\mathrm{e}$ dois o número "ideal" de famílias por projeto, com o objetivo de expandilo (Buainain et al., 2002, p. 94), o que reduziu ainda mais o volume de recursos disponíveis para investimentos complementares. 
muito, à diretoria (...). Há um acompanhamento mais direto e intenso no momento da criação das associações e da adesão ao Programa. A partir daí a presença dos técnicos é irregular e se restringe a questões pontuais. (BUAINAIN et al., 1999, p. 109)

A precariedade do serviço de assistência técnica e do acesso ao crédito foi identificada como principal fator de restrição ao desenvolvimento produtivo dos projetos (BUAINAIN et al., 2003, p. 151). Em relação à prestação de assistência técnica, durante o ano 2002-03, 65,8\% dos entrevistados declararam nunca, ou apenas esporadicamente, ter recebido esse tipo de serviço. Somente $22 \%$ declararam que o serviço havia sido prestado mensalmente (ibidem, p. 135).

A pesquisa coordenada por Victor e Sauer também detectou a debilidade e, em diversas situações, a completa inexistência de assistência técnica nos projetos do Cédula. Essa foi considerada "ruim, precária e, via de regra, impositiva em relação ao tipo e a forma de organização da produção. A precariedade dos serviços se traduz pela baixa freqüência e pela falta de regularidade dos trabalhos dos técnicos nos projetos" (VICTOR \& SAUER, 2002, p. 49-50).

Além da má qualidade e baixa frequência, Victor e Sauer (2002) constataram a ocorrência de práticas autoritárias por parte dos técnicos responsáveis pela implantação do Cédula, como a imposição de áreas para produção comunitária com base na monocultura, secundarizando os lotes familiares, com o objetivo de produzir excedentes comercializáveis para viabilizar o pagamento do empréstimo. Tal prática não só impunha um elemento estranho à cultura do trabalho familiar, como também reproduzia a lógica da monocultura.

Essa prática recriou a remuneração em diárias dentro dos próprios projetos, na tentativa de garantir o fluxo de força de trabalho necessário para tocar a produção comunitária (VICTOR \& SAUER, 2002). Em vez de contribuir para superar essa forma de exploração, a implementação do Cédula estava exigindo a sua recriação dentro dos projetos financiados, transformando os mutuários em "empregados" de suas próprias associações.

A assistência técnica prevista no Cédula padecia de dois problemas estruturais (VICTOR \& SAUER, 2002). Primeiro, esse tipo de serviço era privatizado e pago com recursos do SIC, financiado pelo BIRD. Na prática, essa situação subordinava o gasto com a assistência técnica à administração daquela verba, suscetível a cortes ou remanejamentos de última hora. Segundo, a prestação desse serviço tinha previsão de um ano, renovável por mais um, dependendo da disponibilidade de recursos. É um tempo insuficiente para capacitar as famílias, inclusive devido, na grande maioria dos casos, à baixa periodicidade e à péssima qualidade com que o serviço era realizado. 
As terras compradas por meio do Cédula eram de baixa qualidade e estavam concentradas em regiões menos dinâmicas e mais empobrecidas, o que representou mais um fator de dificuldade ao desenvolvimento produtivo dos projetos. Isso fazia parte da própria lógica do Cédula, uma vez que "o limite de recursos para a aquisição das áreas, em geral, leva a implantação dos projetos em regiões menos dinâmicas, comprando terras menos valorizadas; portanto, fracas e com sérias limitações de produção" (VICTOR \& SAUER, 2002, p. 55-56). Daí o problema insolúvel de projetos como o Cédula: se compram imóveis baratos, cai a qualidade da terra e das benfeitorias e a quantia necessária para a construção de infraestrutura e investimentos produtivos tem de aumentar; se adquirem imóveis mais caros, o empréstimo extrapola a capacidade de endividamento das famílias, gerando um quadro de inadimplência.

Em relação à renda anual auferida, Buainain et al. (2003, p. 63-68) avaliaram uma amostra de 313 beneficiários, entre agosto de 2002 e julho de 2003, chegando a uma renda bruta média de aproximadamente $\mathrm{R} \$ 5.777,05$, o que dava uma renda mensal por família de $\mathrm{R} \$ 483,64$, equivalente a 2,1 salários-mínimos de $R \$$ 240,00 (valor vigente de maio de 2003 a maio de 2004). Quando essa amostra foi distribuída por estratos, percebeu-se que: a) $25 \%$ das famílias continuavam auferindo renda bruta mensal equivalente a um salário-mínimo; b) outros $25 \%$ das famílias obtinham renda bruta mensal de 1 a 1,4 salários; c) o restante das famílias teve renda superior a 1,4 salários mensais, variando entre a larga faixa de $\mathrm{R} \$ 4.253,00$ a $\mathrm{R} \$ 19.894,00$ por ano. Tudo indicava que um pequeno grupo de beneficiários (cerca de 10\%) obteve renda bem superior aos demais, de modo que a média geral de renda por família foi puxada para cima.

A necessidade de assalariamento precário (venda ou aluguel de dias de serviço) não havia sido superada, na medida em que a maioria relatou que, em virtude das dificuldades de produção e comercialização, a venda da mão-de-obra continuava sendo necessária (VICTOR \& SAUER, 2002, p. 40-44). Já, em 2002, o relatório (BUAINAIN et al., 2003, p. 177) assinalou que o peso da atividade agropecuária na composição da renda havia aumentado significativamente, diminuindo a importância relativa do assalariamento temporário, embora persistisse a dependência em relação à renda proveniente de aposentadorias e pensões. Se os resultados indicavam uma elevação da renda em relação à situação anterior à entrada no programa, o quadro apresentado estava longe dos prognósticos de excelência tecidos sobre o Cédula:

As famílias (...) conseguem hoje em geral retirar da produção agropecuária uma renda superior à que tinham antes do projeto, mas que nem sempre é suficiente para sua subsistência. Muitos assentados complementam sua renda agropecuária com a venda de sua força de trabalho e com diversas transferências governamentais (...). Alguns 
assentamentos visitados encontravam-se em situação muito difícil, com poucas famílias estabelecidas e com níveis de renda agropecuária baixíssimos. (BUAINAIN et al., 2003, p. 172)

A produção agrícola foi considerada de subsistência na maioria dos projetos. Apenas dois (entre os dezesseis projetos pesquisados) indicaram a existência de produção de excedentes comercializáveis (VICTOR \& SAUER, 2002, p. 54), portanto, havia dificuldades para uma inserção mercantil efetiva. Quanto ao perfil da produção agropecuária, concluiu-se que a produção permaneceu concentrada na produção vegetal (basicamente de lavouras temporárias), com baixíssimo grau de incorporação tecnológica e realizada de modo individual, contrariando as expectativas iniciais de que a pauta de produção agrícola mudaria, a dimensão associativa ganharia impulso e o nível tecnológico sofreria um salto de qualidade (BUAINAIN et al., 2003, p. 104).

As dificuldades encontradas na aplicação dos recursos destinados à infraestrutura produtiva, a falta de acesso à assistência técnica e outros problemas mostravam que, em 2002 - ano em que o Cédula foi concluído - parte significativa das famílias enfrentava dificuldades sérias para gerar renda suficiente, tanto para melhorar de vida como para amortizar a dívida contraída. Realizada ainda no período de carência de muitos projetos, a pesquisa (VICTOR \& SAUER, 2002) não conseguiu obter informações oficiais sobre o pagamento da dívida imobiliária. Estava colocada, no entanto, uma situação de inadimplência, pois "perguntadas sobre as condições financeiras, as pessoas entrevistadas foram praticamente unânimes em afirmar que não há condições para efetuar o pagamento da primeira parcela do financiamento" (ibidem, p. 63).

Embora seja o relatório final da consultoria externa financiada pelo BIRD e muitos projetos já tivessem mais de quatro anos de existência quando a pesquisa de campo foi realizada (agosto de 2002 a julho de 2003), o relatório de Buainain et al. (2003) também não trouxe informações sobre o pagamento da dívida contraída com a compra da terra. Constam apenas projeções sobre a evolução da renda agropecuária familiar anual nos principais sistemas agrícolas desenvolvidos nos projetos pesquisados. Apesar do interessante exercício de projeção econométrica sobre possíveis rendas (BUAINAIN et al., 2003, p. 157-170), nem o Banco Mundial, nem o governo federal disponibilizaram informações consistentes sobre o pagamento das prestações por parte das famílias.

Não há transparência dos gestores públicos sobre o pagamento das prestações do Cédula, do Banco da Terra, nem mesmo do Crédito Fundiário. Já em 2003, todavia, um indicativo da "existência de um quadro de irregularidades e desestruturação de muitos projetos" (MDA, 2004, p. 1) foi a elaboração de um plano de "recuperação e regularização dos projetos financiados pelo Fundo de Terra" 
(ibidem). Reconhecendo uma série de problemas e fragilidades dos "programas de crédito fundiário" devido às "condições de financiamento e itens financiados", o objetivo deste documento foi retirar os projetos financiados pelo Banco da Terra e Cédula "da situação de passivo" (ibidem).

A resolução correspondente a este plano não tratou diretamente, mas pressupôs o reescalonamento de dívida sob responsabilidade das associações e cooperativas (MDA, 2006, art. 25), abrindo a possibilidade de individualização nos casos em que essas entidades "não conseguirem arcar com a dívida decorrente do financiamento" (ibidem, art. 33). Não resta dúvida de que a publicação dessa resolução foi motivada pela existência de problemas sérios de inadimplência, constatadas (em documento interno) pelo próprio MDA, em 2007/2008, quando do processo de renegociação das dívidas agrícolas (SAUER, 2010).

Além dos problemas de inadimplência, a pesquisa de Victor e Sauer (2002) apontou diversos indícios de desvio de finalidade, favorecimento e corrupção em inúmeros projetos, como a elaboração de laudos técnicos fraudulentos, o superfaturamento de imóveis rurais, a compra de várias áreas de uma mesma empresa ou proprietário, a aquisição de imóveis localizados em regiões de Mata Atlântica, o conluio entre prefeituras e proprietários de terras, entre outros.

\section{A reforma agrária "assistida pelo mercado" no governo Lula}

Em 2003, o Banco da Terra e o Crédito Fundiário de Combate à Pobreza Rural estavam em andamento, sendo que o primeiro não era apenas um programa, mas um fundo de financiamento à compra de terras, criado pelo Congresso Nacional, se constituindo em um programa permanente. O Crédito Fundiário, por sua vez, foi criado a partir de um acordo de empréstimo com o BIRD e estava apenas começando a ser implantado em 2003.

A decisão governamental foi a de não somente lidar com o passivo existente, mas também ampliar a implantação da RAAM com metas maiores que o governo anterior. $\mathrm{O}$ então recém eleito presidente se comprometeu publicamente com a reforma agrária por meio das desapropriações, mas avalizou a RAAM. Essa estranha combinação apareceu nas metas do II Plano Nacional de Reforma Agrária (PNRA II), onde constavam as metas de financiar a compra de terra por parte de 130 mil famílias em quatro anos, enquanto a reforma agrária abarcaria 400 mil famílias (MDA, 2003).

Em termos absolutos, os programas de financiamento à compra de terras representaram bem mais do que o governo anterior conseguiu pôr em prática. Em termos relativos, representaram mais de 30\% da meta da "reforma agrária", 
14. De acordo com o $\operatorname{MDA}(2005$, p.1), a auditoria resultou "na abertura de processos administrativos, que por sua vez se desdobraram em inquéritos policiais, comissões de sindicância e outros instrumentos de apuração de responsabilidades administrativa, civil e criminal". o que compromete o discurso oficial sobre o seu caráter "complementar". Em outras palavras, sem criminalizar a luta por terra e contando com o apoio de todos os movimentos sociais agrários e entidades sindicais de representação de trabalhadores rurais, o governo Lula (2003-2010) conseguiu operar uma espécie de acomodação entre a reforma agrária constitucional e os programas de financiamento para a compra de terras, financiados pelo Banco Mundial (SAUER, 2010; PEREIRA, 2010).

O governo Lula: a) criou o Programa Nacional de Crédito Fundiário (PNFC), responsável pela gestão do Fundo de Terras e dos programas e projetos nessa área; b) manteve o programa Banco da Terra sob um novo nome (Consolidação da Agricultura Familiar), com algumas reformulações; c) implementou, de fato, o Crédito Fundiário de Combate à Pobreza Rural; d) criou linhas de financiamento como, por exemplo, para jovens agricultores e quilombolas comprarem terra; e) reformulou o Fundo de Terras, a fim de usá-lo como contrapartida nacional aos empréstimos do BIRD para os programas de compra de terras (PEREIRA, 2010; SAUER, 2010).

No início de 2003, o Ministério do Desenvolvimento Agrário (MDA) realizou uma auditoria interna no Banco da Terra, como uma resposta aos inúmeros indícios de irregularidades e aos questionamentos dos movimentos sociais. Embora os resultados da auditoria não tenham sido abertos à consulta pública, o MDA anunciou a sua suspensão, alegando a existência de problemas sérios em sua gestão ${ }^{14}$. Divulgou-se que o programa havia financiado 34.759 famílias, em 18.294 operações, totalizando 2.537 .621 hectares, ao custo de $\mathrm{R} \$ \mathbf{7 4 4 . 2 1 6 . 7 4 6}$ (MDA, 2004, p. 1).

Corroborando as denúncias feitas pelo FNRA, entre 1998 e 2000, o MDA assinalou que os mecanismos de gestão do Banco da Terra, sob o governo FHC, eram "frágeis" e haviam permitido "o surgimento de uma série de irregularidades, entre as quais, por exemplo, o financiamento da compra de áreas de proteção ambiental ou de terras com títulos de propriedade duvidosos, que não podem ser exploradas pelos beneficiários" (MDA, 2005, p. 2). Naquele momento, segundo o MDA, havia "mais de 82 sindicâncias ou processos administrativos abertos, além de várias irregularidades em exame nas instâncias de controle interno e externo do governo (CGU/SFC e TCU)" (MDA, 2005). Sem surpresa, mas sem maiores detalhes, afirmou-se que o programa tinha levado vários empreendimentos financiados ao "sobreendividamento" (MDA, 2005).

No contexto da avaliação do Banco da Terra, o Governo Lula fez uma reestruturação ou reformulação do mesmo, criando então o Programa Nacional de Crédito Fundiário (PNCF). Na prática, esse programa unificou a gestão das linhas de financiamento do Crédito Fundiário e do Banco da Terra/Fundo de Terras 
e os alocou na Secretaria de Reordenamento Agrário (SRA) do MDA, mantendo a mesma lógica da RAAM (PEREIRA, 2010).

Foram, então, feitas algumas reformulações nos itens financiáveis e nas condições de financiamento oferecidas pelo Banco da Terra, aumentando um pouco o subsídio embutido no crédito (BANCO CENTRAL, 2003), o denominando de Consolidação da Agricultura Familiar (SAUER, 2010). A lógica permaneceu basicamente a mesma, ou seja, financiar a compra de terra por trabalhadores rurais sem terra e pequenos agricultores, preferencialmente nos quatorze estados que não foram incluídos no empréstimo do Banco Mundial para o Crédito Fundiário de Combate à Pobreza Rural (MDA, 2005a, p. 4).

A fim de implantar o programa - ou uma linha do PNCF - Consolidação da Agricultura Familiar no maior número possível de estados, o MDA passou a firmar termos de cooperação com governos estaduais a partir do final de 2003 (MDA, $2005 a$, p. 8). Sua fonte de financiamento tem sido exclusivamente nacional, ou seja, recursos orçamentários alocados no Fundo de Terras, sem o aporte de recursos do Banco Mundial (MDA, 2004a).

A implantação do Crédito Fundiário, que deu sequência ao Cédula da Terra e passou a contar com a participação dos sindicatos de trabalhadores rurais (STRs), começou a operar de fato apenas a partir de 2004, razão pela qual sua conclusão foi adiada para 2006 (MDA, 2005, p. 4). Com essa prorrogação, a sua implantação e o seu desempenho inicial devem ser creditados inteiramente ao governo Lula, renomeado como "Combate à Pobreza Rural", uma linha do PNFC que abrange os quatorze estados. Em 2000, a diretoria do BIRD já havia aprovado mais duas outras fases (ou empréstimos), as quais, se executadas, prolongariam o projeto até 2012, financiando a compra de terras por cerca de 190 mil famílias (MDA, 2003, p. 15).

Outra ação do governo Lula foi a criação de uma linha de financiamento para compra de terra dirigida a jovens agricultores. Chamada "Nossa Primeira Terra", tem como público alvo a população rural pobre entre 18 e 24 anos nos três estados da região Sul. Conta com o apoio dos STRs e das Federações Estaduais de Trabalhadores Rurais ligadas à CONTAG e da Federação de Trabalhadores da Agricultura Familiar (FETRAF).

O governo Lula, ainda, reestruturou o Fundo de Terras/Banco da Terra. Sob uma nova regulamentação ${ }^{15}$, esse instrumento foi oficializado como a fonte financiadora de todos os programas de "crédito fundiário" em curso, viabilizando a contrapartida nacional aos empréstimos do Banco Mundial. Esse Fundo foi reorganizado para ter sustentabilidade financeira e operar durante um longo período com uma projeção inicial de trinta anos de ação ininterrupta
15. Embora o decreto $\mathrm{n}$ ㅇ 4.892, de novembro de 2003, que regulamentou o Fundo, tenha aberto a possibilidade de que os recursos nele aportados fossem também utilizados para a construção de infraestrutura nos projetos criados pelo programa de reforma agrária, nenhum percentual foi estabelecido. 
16. “O Programa Nacional de Crédito Fundiário teve suas normas e diretrizes elaboradas a partir de 2003, apoiandose apenas na Lei Complementar 93/98. Conforme esclarecido no preâmbulo deste documento, o Programa não é, em absoluto, uma continuidade do Banco da Terra ou do Cédula da Terra" (MDA, 2005, p. 7).

17. Segundo o BIRD, "o projeto [Crédito Fundiário] foi precedido por dois pilotos muito bemsucedidos, financiados pelo Banco, e será seguido por futuras operações de apoio ao programa governamental de reforma agrária comunitária. O primeiro piloto foi implementado como um componente dentro do Projeto de Alívio da Pobreza Rural do Ceará (Loan 3918$B R)$, e o segundo foi o Projeto Piloto de Reforma Agrária e Alívio da Pobreza (Loan 4147-BR, conhecido no Brasil como Projeto Cédula da Terra)" (Banco Mundial, 2000a, item $\mathrm{A}$, ponto 1 ).
(MDA, 2003). Desse modo, poderia funcionar como uma grande imobiliária pública subsidiada. A existência desse instrumento explicita a perspectiva de que os programas de financiamento à compra de terras passaram a assumir a lógica e o status de política de Estado (PEREIRA, 2010).

De acordo com Medeiros (2007, p. 1511), cerca de 85 mil famílias compraram terra através de programas RAAM, entre 1997 e 2006, incluindo 35.564 famílias financiadas com recursos do PNCF entre 2003 e 2006. Isso aponta para o fato de que o governo Lula não atingiu a sua própria meta de financiar 130 mil famílias no período de 2003 a 2006. O MDA (2005) não deu nenhuma justificativa para o baixo desempenho na execução dos programas. Contudo, ao menos dois fatores influenciaram no baixo desempenho: as dificuldades recorrentes do MDA resultantes dos cortes orçamentários e a elevação dos preços das terras em função da dinamização do grande agronegócio nos anos mais recentes (DELGADO, 2010).

O governo Lula manteve o discurso que negava a continuidade entre o PNCF e os programas anteriores do governo $\mathrm{FHC}^{16}$, o que o colocava em contradição com os documentos do próprio Banco Mundial (2000a) $)^{17}$. Por outro lado, não procede o discurso oficial de que o PNCF não concorre com os recursos públicos destinados ao programa de "reforma agrária". É verdade que o Fundo de Terras se constitui em uma fonte distinta, mas também são recursos públicos, previstos no Orçamento Geral da União (SAUER, 2010). Ademais, as famílias "são parte integrante da Reforma Agrária e têm, como os beneficiários dos demais programas, acesso às políticas de financiamento e de apoio previstos nos programas do MDA" (MDA, 2004, p. 9).

As pressões para renegociar as dívidas dos programas de RAAM, em 2007/2008 e novamente em 2010/2011, evidenciam que o endividamento é um fato. De acordo com documento interno do Ministério da Fazenda (2008, p. 19), foram celebrados 17.834 contratos sob a égide do Cédula e do Banco da Terra até 2004. Destes, 5.097 contratos (mais de $28 \%$ do total) estavam com as parcelas atrasadas (as famílias estavam inadimplentes com o banco), em julho de 2007 (SAUER, 2009).

Outro documento avaliou esse cenário como "extremamente crítico", pois "o percentual de inadimplência acumulada, apurada até o mês de dezembro/2006, corresponde a $66,46 \%$ do total previsto para reembolso no período, equivalente a R\$95.109,205,69" (MDA, 2007, p. 2). As famílias envolvidas, diante da impossibilidade de pagar as prestações, pediram uma renegociação das dívidas, com maiores rebates, taxas de juros menores e prazos mais longos para a amortização do saldo devedor, já que não poderão quitar em vinte anos, conforme regras estabelecidas. 
Atendendo às solicitações, as famílias envolvidas nos programas de compra de terras foram incluídas na Medida Provisória no 432/2008, permitindo a renegociação das dívidas atrasadas (SAUER, 2009 e 2010). Essa mesma MP (aprovada no Congresso e convertida na Lei no. 11.775, de 17 de setembro de 2008), além de estabelecer as regras dessa renegociação, estabeleceu novas taxas de juros para todos os contratos de empréstimos tanto do Crédito Fundiário (art. 24), como do Banco da Terra (art. 25) (PRESIDÊNCIA, 2008). O ônus dessa renegociação, inclusive as diferenças nas taxas de juros, é responsabilidade do Fundo de Terras e da Reforma Agrária (art. 24, § único, e art. 25, § 3ㅇ), ou seja, recursos públicos alocados no Orçamento Geral da União (SAUER, 2010).

Resumindo, o governo federal foi obrigado a renegociar as dívidas das famílias envolvidas nos programas de compra de terras, com gasto adicional de recursos públicos, mas pairam dúvidas sobre a existência de uma saída viável para esse processo. Por diferentes razões, as famílias não tiveram - e não se sabe se terão - condições de pagar as dívidas contraídas com a compra de terra via programas da "reforma agrária de mercado".

\section{Conclusões}

A priori, não há por que descartar a hipótese de que seja possível melhorar tecnicamente quaisquer políticas públicas, aumentando a sua eficácia mediante, p. ex., o combate ao clientelismo e à corrupção, a promoção de auditorias, a concessão de mais espaço para a participação autônoma dos interessados, etc. Entretanto, para além de questões relativas ao desenho e à execução dos programas, as limitações fundamentais dos programas orientados pelo modelo de RAAM decorrem da sua dinâmica excludente, derivada da correlação de forças que está na sua raiz e do tipo de matriz política que lhe confere substrato e gravitação social. Em situações como essa, argumentou Vilas (1997), os esforços para melhorar a eficácia das políticas de acesso à terra deveriam ser encarados como parte de um redesenho de tipo macropolítico.

Em curso desde 1997, a experiência brasileira com programas de "reforma agrária assistida pelo mercado", vinculados ou não ao Banco Mundial, é a mais significativa em escala internacional. Em nenhum outro país se gastou tanto dinheiro público e se contratou tal volume de empréstimos com o BIRD para financiar a compra de terras como no Brasil (PEREIRA, 2010).

Iniciado, não por acaso, em um contexto de intensa polarização política, o projeto piloto Cédula da Terra e, sobretudo, o Banco da Terra, angariaram a adesão imediata de entidades de representação do patronato rural, a exemplo da Confederação Nacional da Agricultura (CNA), não apenas por remunerarem os 
proprietários à vista e a preço de mercado, mas, sobretudo, por competirem com a mobilização popular por reforma agrária (PEREIRA, 2010). Em 2005, a defesa desse tipo de programa como instrumento praticamente exclusivo de política agrária foi mais uma vez reiterada publicamente por porta-vozes do patronato rural (LUPION, 2005).

A disputa política com os movimentos sociais agrários acabou resultando, da parte do BIRD e do Executivo Federal, o discurso de que tais programas, além de baratos e eficientes, configurariam uma espécie de "reforma agrária baseada na comunidade". Todavia, as diversas pesquisas citadas neste artigo evidenciaram a fragilidade das associações e o seu baixo grau de protagonismo, não só na negociação das terras, mas também na condução do processo organizativo. A maioria dessas associações foi constituída tão somente para cumprir exigências burocráticas do programa, e não como mecanismos ou ferramentas de mobilização política e protagonismo social na luta pelo acesso à terra. Por outro lado, a implantação desses projetos serviu ao propósito de esvaziar a mobilização social pelo acesso à terra mediante ocupações coletivas (SAUER, 2010; PEREIRA, 2010).

Mesmo com todas as limitações de acesso à informação, já existe um acúmulo significativo de pesquisas empíricas sobre a implantação e o desenvolvimento de, pelo menos, uma dessas experiências: o Cédula da Terra. A leitura que aqui se fez desses estudos procurou questionar as supostas vantagens do modelo de RAAM e dos programas nele inspirados. Contudo, o aggiornamento da RAAM sob o governo Lula, propiciado pelo apoio da maior entidade nacional de representação de trabalhadores rurais, a CONTAG, deu novas condições para o Banco Mundial buscar legitimar, na arena nacional e internacional, o seu modelo de acesso à terra pela via da compra e venda.

Abstract: This article surveys the implementation and results of a pilot project called Cédula da Terra (1997-2002) and its continuity through the National Credit for Land, after 2003, in Brazil. These programs were inspired in a model called "market-assisted land reform", financed by the World Bank and implemented in several countries, particularly in Latin America, starting in 1994 as an alternative to agrarian reform, which is basically active in Brazil today. Based on data of empirical researches it is argued that the Cédula da Terra was not well-succeeded in providing a model of access to land replicable on a larger scale, as the World Bank has been arguing. Furthermore, the article evaluates the developments of this model in the land policies of Luis Inácio Lula da Silva's Government (2003-2010).

Keywords: World Bank, Cédula da Terra, Agrarian Credit, Rural Poverty, Agrarian Reform. 
Referências Bibliográficas

BANCO CENTRAL. Decreto no. 4.892. Brasília: 25 de novembro, 2003.

BANCO MUNDIAL. Land policies for growth and poverty reduction. Washington DC, 2003b. 25973, 2003a.

Implementation completion report. Washington DC: Report no . Rural poverty alleviation in Brazil: toward an integrated strategy. Washington DC, 2003. . Country Assistance Strategy - Brazil (2000-2002). Washington DC, 2000.

. Project Appraisal Document (PAD) on a proposed loan in the amount of EUR 218.2 million (US\$ 202.1 million equivalent) to the Federative Republic of Brazil for a land-based poverty alleviation project I. Washington DC: Report no 19585-BR, 6 de novembro, 2000a.

. Proyecto Fondo de Tierra - Guatemala. Washington DC: Reporte no PID 6829, julho, 1998. . Country assistance strategy - Brazil (1997-1999). Washington DC,

1997. . Land reform and poverty alleviation pilot project. Report $\mathrm{n}$ - PIC 4974, Washington DC, 1997a.

. Project appraisal document to Brazil for land reform and poverty alleviation pilot project. Washington DC: Report no 16342-BR, $1997 \mathrm{~b}$. . Brazil: a poverty assessment. Washington DC: Report no 14323BR, 1995.

BANERJEE, Abhijit. Land reforms: prospects and strategies. Washington DC: Conference Paper, Annual World Bank Conference on Development Economics, 1999.

BARROS, Flávia, SAUER, Sérgio; SCHWARTZMAN, Stephen (orgs.) Os impactos negativos da política de reforma agrária de mercado do Banco Mundial. Brasília: Rede Brasil/MST/Via Campesina/FIAN/Environmental Defense/CPT, 2003. 
BORRAS JR., Saturnino M. "The underlying assumptions, theory, and practice of neoliberal land policies" In: Peter Rosset, Raj Patel; Michael Courville (eds.), Promised lad: competing vision of agrarian reform. Oakland: Food First Books, 2006.

- "Questioning market-led agrarian reform: experiences from Brazil, Colombia and South Africa". Journal of Agrarian Change, vol. 3, July, 2003, p. 367-394.

. "Questioning the pro-market critique of state-led agrarian reforms". European Journal of Development Research, vol. 15 (2), December, 2003a, p. 109-132, .

BUAINAIN, Antônio Márcio et al. Estudo de avaliação de impactos do programa Cédula da Terra. Brasília: UNICAMP/NEAD/MDA, relatório final, novembro, 2003.

. Estudo de avaliação de impactos do programa Cédula da Terra. Brasília: UNICAMP/NEAD/MDA, relatório síntese, novembro, 2002.

. Relatório preliminar de avaliação do Projeto Cédula da Terra. Brasília: UNICAMP/NEAD/MEPF, junho, 1999.

BUAINAIN, Antônio M.; SILVEIRA, José M. da; TEÓFILO, Edson. “O programa Cédula da Terra no contexto das novas políticas de reforma agrária, desenvolvimento e participação: uma discussão das transformações necessárias e possíveis" In: Pedro Sisnando Leite (org.), Reforma agrária e desenvolvimento sustentável. Brasília: MDA/NEAD, 2000.

BURKI, Shahid Javed; PERRY, Guillermo. The long march: a reform agenda for Latin America and the Caribbean in the next decade. Washington DC: The World Bank, 1997.

CARDOSO, Fernando Henrique. "Terra e cidadania". Folha de S. Paulo, 24 de março, 1995.

República, 1997.

. Reforma agrária: compromisso de todos. Brasília: Presidência da

CARVALHO Fo, José Juliano de. "Política agrária do governo FHC: desenvolvimento rural e a Nova Reforma Agrária" In: Sérgio Leite (org.), Políticas públicas e agricultura no Brasil. Porto Alegre: EDUFRGS, 2001. 
DEININGER, Klaus; BINSWANGER, Hans. "The evolution of the World Bank's land policy: principles, experience and future challenges". The World Bank Research Observer, vol. 14 (2), agosto, 1999, p. 247-275.

DE JANVRY, Alain; SADOULET, Elisabeth. "Access to land and land policy reforms", In: Alain de Janvry et al. (eds.), Access to land, rural poverty, and public action. London: Oxford University Press, 2001.

DELGADO, Guilherme. "A questão agrária e o agronegócio no Brasil”, In: Miguel Carter (org.), Combatendo a desigualdade: o MST e a reforma agrária no Brasil. São Paulo: Editora UNESP, 2010.

EL-GHONEMY, M. Riad. "The political economy of market-based land reform", In: Krishna B. Guimire (ed.), Land reform and peasant livelihoods: the social dynamics of rural poverty and agrarian reforms in developing countries. London: ITDG Publishing, 2001.

FÓRUM Nacional pela Reforma Agrária e Justiça no Campo. Segunda solicitação ao Painel de Inspeção. Brasília: 27 de agosto, 1999.

GAROZ, Byron et al. Balance de la aplicación de la política agraria del Banco Mundial en Guatemala (1996-2005). Guatemala: CONGCOOP, octubre, 2005.

GORDILLO, Gustavo. Economía política de los derechos de propiedade de las instituciones agrarias en América Latina. Texto apresentado no Taller regional sobre asuntos de tierras en Latinoamérica y el Caribe, Pachuca, Hidalgo, maio, promovido pelo Banco Mundial, 2002.

JARAMILLO, Carlos Felipe. "El mercado rural de tierras en América Latina: hacia una nueva estrategia", In: Banco Interamericano de Desenvolvimento (ed.), Perspectivas sobre mercados de tierras rurales en América Latina. Informe Técnico no 124, Departamento de Desarrollo Sostenible, División de Medio Ambiente, 1998.

LAHIFF, Edward, BORRAS JR. Saturnino e KAY, Cristóbal. “Market-Led Agrarian Reform: policies, performance and prospects". Third World Quarterly, vol. 28 (8), Special Issue, 2007, p. 1417-1436.

LUPION, Abelardo. Relato dos trabalhos da CPMI "da Terra" - Voto em separado. Brasília: Congresso Nacional, novembro (mimeo), 2005.

MEDEIROS, Leonilde Sérvolo de. "Social movements and the experience of market-led agrarian reform in Brazil". Third World Quarterly, vol. 28, no 8, 2007, p. 1501-1518. 
. Movimentos sociais, disputas políticas e reforma agrária de mercado no Brasil. Rio de Janeiro: CPDA/UFRRJ e UNRISD, 2002.

MDA. Alteração das condições e repactuação dos projetos contratados com recursos do Fundo de Terras e da Reforma Agrária - Banco da Terra. Brasília (documento interno - não publicado), 2007.

. Resolução no 2. Brasília: MDA/CONDRAF, 21 de junho, 2006.

. Ofício no 40/2005-MDA. Brasília: 27 de abril, 2005.

. Programa Nacional de Crédito Fundiário: Consolidação da Agricultura Familiar - Manual de Operações. Brasília, novembro, 2005a.

. Programa Recuperação e Regularização dos Projetos financiados pelo Fundo de Terras (Programas Banco da Terra e Cédula da Terra). Brasília: Departamento de Crédito Fundiário, 2004.

. Fundo de Terras e da Reforma Agrária - Regulamento Operativo. Brasília: CONDRAF, 14 de abril, 2004a.

. Programa Nacional de Crédito Fundiário: Projeto de Crédito Fundiário e Combate à Pobreza Rural - Manual Operativo. Brasília: CONDRAF, 30 de março, 2004b.

. Programa Nacional de Crédito Fundiário: Plano anual de aplicação de recursos - 2003/2004. Brasília: 12 de dezembro, 2003. . Il Plano Nacional de Reforma Agrária (II PNRA). Brasília, 2003a.

MEPF. Banco da Terra. Brasília, 1999.

MINISTÉRIO DA FAZENDA. Levantamento das operações de crédito rural do PRONAF, PROCERA e Crédito Fundiário. Brasília: março, 2008.

PEREIRA, João Márcio Mendes. A política de reforma agrária de mercado do Banco Mundial: fundamentos, objetivos, contradições e perspectivas. São Paulo: Hucitec, 2010.

. "The World Bank's 'market-assisted land reform' as political issue: evidence from Brazil (1997-2006)". European Review of Latin American and Caribbean Studies, vol. 82, abril, 2007, p. 21-49.

. "A política agrária do Banco Mundial em questão". Estudos Avançados, vol. 20, n. 57, maio-agosto, 2006, p. 355-383. 
. "A disputa político-ideológica entre a reforma agrária redistributiva e o modelo de reforma agrária de mercado do Banco Mundial (1994-2005)". Sociedade \& Estado, v. 20, n. 3, 2005, p. 611-646.

; SAUER, Sérgio. "História e legado da reforma agrária de mercado no Brasil", In: Sérgio Sauer, João Márcio Mendes Pereira (orgs.). Capturando a terra: Banco Mundial, políticas fundiárias neoliberais e reforma agrária de mercado. São Paulo: Editora Expressão Popular, 2006.

PRESIDÊNCIA DA REPÚBLICA. Lei no. 11.775. Brasília, 17 de setembro, 2008.

SAUER, Sérgio. “'Reforma agrária de mercado' no Brasil: um sonho que se tornou dívida". Estudos Sociedade e Agricultura, vol. 18, no 1, abril, 2010, p. 98-125.

. "Market-led agrarian reform in Brazil: the costs of an illusory future". Progress in Development Studies, vol. 9 (2), 2009, p. 127-140.

. "'A ticket to land': The World Bank's market-based land reform in Brazil”, In: Flávia Barros, Sérgio Sauer e Stephen Schwartzman (orgs.), The negative impacts of World Bank market based land reform. Brasilia: Rede Brasil/MST/ Via Campesina/FIAN/Environmental Defense/CPT, 2003.

; PEREIRA, João M. M. (orgs) (2006) Capturando a terra: Banco Mundial, políticas fundiárias neoliberais e reforma agrária de mercado. São Paulo: Editora Expressão Popular.

STEIL, Carlos Alberto. "Cédula da Terra", In: Maria Clara Couto Soares (coord.) (2001), Estudo sobre fundos sociais e ambientais financiados ou administrados pelo Banco Mundial no Brasil. Rio de Janeiro: Banco Mundial, agosto, 2000.

TEÓFILO, Edson."Brasil: nuevos paradigmas de la reforma agraria”, In: Pedro Tejo (org.), Mercados de tierras agrícolas en América Latina y el Caribe: una realidad incompleta. Santiago do Chile: Nações Unidas/CEPAL/GTZ, vol. 1, 2003.

VAN ZYL, Johan et al. Decentralized rural development and enhanced community participation: a case study from Northeast Brazil. Washington DC: World Bank, Policy Research Working Paper, № 1498, 1995.

VAN ZYL, Johan; KIRSTEN, Johann; BINSWANGER, Hans (eds.) Policies, Markets and Mechanisms for Agricultural Land Reform in South Africa. New York: Oxford University Press, 1996.

VICTOR, Andréa Dias; SAUER, Sérgio (coords.) Estudo sobre a política do Banco Mundial para o setor agrário brasileiro com base no caso do Projeto Cédula da Terra. Brasília: CPT/MST/Rede Brasil/FIAN-Brasil, outubro, 2002. 
VILAS, Carlos M. "De ambulancias, bomberos y policías: la política social del neoliberalismo (notas para una perspectiva macro)". Desarrollo Económico, no 144, enero-marzo, 1997, p. 931-952. 